\title{
Prospective study of children exposed to variable amounts of alcohol in utero
}

\author{
G LARSSON, A-B BOHLIN, AND R TUNELL \\ Departments of Psychiatry and Paediatrics, Karolinska Institute, Huddinge Hospital, Stockholm, Sweden
}

SUMMARY Forty children exposed to variable amounts of alcohol in utero and 40 control children were studied. All mothers had been enrolled in an antenatal programme aiming to identify and reduce alcohol use and abuse during pregnancy. Follow up was at the median age of 22 (18 to 27) months. A significant reduction in intrauterine growth was seen in children born to alcoholic mothers. Three of six children continuously exposed to high amounts of alcohol throughout fetal life showed growth retardation and physical abnormalities characteristic of fetal alcohol exposure, while infants whose mothers had stopped drinking did not suffer these effects. Psychological or behavioural disturbances were found in all but one of 13 children born to alcoholic mothers. The home environment during the first two years did not compensate for the effects of fetal alcohol exposure. Mothers classified as excessive drinkers but not abusers all reduced their alcohol consumption after the first trimester. Their children did not differ from controls with regard to physical development or behaviour but many were retarded in speech and, in addition had a more unstable family background.

A large number of reports describing the teratogenic effects of alcohol have been published since identification of the fetal alcohol syndrome in $1973 .^{1}$ Clinical research shows that offspring of mothers who consume large quantities of alcohol during pregnancy are at high risk of physical and mental deficiencies. $^{23}$ Few prospective studies, however, deal with the fetal effects of interrupted alcohol consumption during pregnancy as a result of an intervention programme.

An antenatal programme was started to help pregnant women stop alcohol abuse thereby reducing the effects of alcohol on the fetus. A detailed report of this programme has been published elsewhere. ${ }^{4}$ In Sweden, $99 \%$ of pregnant women attend a local maternal health clinic for antenatal care and two of these clinics were involved in this programme. The midwives cooperated with two social workers who interviewed all pregnant women on their drinking and smoking habits, drug abuse, and social situation. A reference group comprising a social worker, obstetrician, paediatrician, and psychiatrist were available for consultation. The aim of the present study was to investigate the physical and psychological development and the family situation of the children in relation to the drinking habits of the mothers during pregnancy.

\section{Population}

The follow up study included children born to mothers who were enrolled in the above mentioned programme. The children were classified into three groups according to the maternal use or abuse of alcohol identified by the antenatal staff. A total of 80 children were studied. The median age of the children at the time of the follow up was 22 (18 to 27) months.

Group 1. This group comprised 40 children who served as controls. Each had been born next in chronological order to a proband child of the same sex (groups 2 and 3). Individual alcohol consumption of the mothers of these children averaged less than $30 \mathrm{~g}$ of pure alcohol per day $(10 \mathrm{~g}$ of pure alcohol corresponds to $3 \mathrm{cl}$ of $40 \%$ liquors or $10 \mathrm{cl}$ of $12 \%$ wine) during the month before their first visit to the maternal health clinic, and six were abstainers. All mothers stated in an interview after the delivery that they had minimised or abstained from alcohol after the first visit to the clinic. Seven 
mothers were heavy smokers (more than 20 cigarettes per day). The median age at delivery was 26 (19 to 37$)$ years.

Group 2. There were 25 children in this group. The mothers of these children were classified as excessive drinkers and had an average consumption of 30 to $125 \mathrm{~g}$ of pure alcohol per day during the month before their first visit to the clinic. In an interview after delivery all mothers declared that they had reduced their alcohol consumption after their first visit and 19 had abstained. Eight mothers were heavy smokers. The median age at delivery was 26 (19 to 34$)$ years.

Group 3. This group comprised 15 children of alcoholic mothers who had an average consumption of more than $125 \mathrm{~g}$ of pure alcohol per day during the month before their first visit to the clinic. Six mothers were admitted to the antenatal programme from other maternal health clinics in the area. Nine mothers in this group stopped drinking alcohol during the first or second trimester but the remaining six continued throughout the pregnancy. Seven mothers were heavy smokers. The median age at delivery was 31 (19 to 41 ) years. To validate the women's reports of reduced alcohol consumption records of the social welfare authorities, psychiatric clinics, and of the outpatient unit for alcoholics were studied. The social and physical rehabilitation as well as abstention were verified in the records.

The median time of the first examination at the clinic was the 10th week of pregnancy in groups 1 and 2 and the 15th week in group 3 . All women except five in group 3 paid nine visits or more to the clinic and these five abused alcohol throughout pregnancy. The mothers in the study belonged to working and lower middle class socioeconomic groups. The women in group 3 were significantly older at delivery than those in the other two groups $(P<0.01)$. No woman in any of the groups used drugs apart from tobacco and alcohol.

Analysis of those who failed follow up. Information from records on the health, growth, and social situation was collected for all children. At follow up the physical and psychological examinations could not be performed in five (the physical examination in four) children in group 2 (three parents refused, one emigrated, one moved to an unknown address) and two children in group 3 (one dead, one mother in hospital). The information from the records concerning these seven did not differ from that on the remaining population in each group.

\section{Methods}

Physical health. Information about pregnancy, delivery, and the newborn infant was collected from records in the departments of obstetrics and paediatrics. All children were followed at the local well baby clinic and these records as well as hospital records were studied. At follow up the children were examined by a paediatrician following a protocol (available on request) focusing on the abnormalities and features characteristic of fetal alcohol syndrome. ${ }^{5}$ The paediatrician was not informed of the group classification of the child.

Psychological development. A psychologist who had no knowledge of the child's group classification examined the children in their homes. Griffiths development scales were used. ${ }^{67}$ The evaluation of the children's behaviour focused on activity rate, attention span, ability to establish contact, extent of anxiety, and depressive behaviour.

Family situation. A social worker interviewed the mothers in their homes according to a structured protocol with regard to their drinking habits, social situation, and experience of parenthood. If the child was in foster care, the biological mother was not contacted, but the foster parents were. In addition, information was obtained from the social welfare records.

Statistical methods and ethics. Student's $t$ test, $\chi^{2}$ test, Fisher's exact test, and Wilcoxon rank sum test were used for the statistical analyses. The study was approved by the ethical committee of the Karolinska Institute.

\section{Results}

\section{Physical health.}

\section{Neonatal period}

Weights, heights, and head circumferences at birth are shown in Table 1 . A statistically significant reduction in all three parameters was seen in group 3 compared with group 1 . Four of 15 infants in group 3 but none in the other groups were small for gestational age (weight below - 2SD compared with healthy Swedish infants) (personal communication). When comparing term babies, the differences remain, with the exception of head circumferences. The mean birthweight of the infants of mothers who smoked heavily did not differ from that of the others in either of the groups.

In group 1 nine of $\mathbf{4 0}$ infants had some negative notation concerning health in the birth record 
Table 1 Growth and status at birth (values, mean (SD))

\begin{tabular}{|c|c|c|c|}
\hline & Group 1 & Group 2 & Group 3 \\
\hline All infants & $(n=40)$ & $(n=25)$ & $(n=15)$ \\
\hline Weight & $3529(505)$ & $3428(640)$ & $2834(677)^{8}$ \\
\hline Height & $51.3(2.0)$ & $50 \cdot 6(2 \cdot 8)$ & $48.8(3.0)$ \\
\hline Head circumference & $34 \cdot 6(1 \cdot 3)$ & $34.9(1.8)$ & $33 \cdot 4(2 \cdot 1)$ \\
\hline $\begin{array}{l}\text { Number of preterm } \\
\text { infants }\end{array}$ & 0 & 2 & 2 \\
\hline $\begin{array}{l}\text { Apgar score }<7 \text { at } \\
1 \mathrm{~min}\end{array}$ & 0 & 1 & 2 \\
\hline $\begin{array}{l}\text { Term infants } \\
\text { Weight } \\
\text { Height } \\
\text { Head circumference }\end{array}$ & $\begin{array}{l}(n=40) \\
3529(505) \\
51 \cdot 3(2 \cdot 0) \\
34 \cdot 6(1 \cdot 3)\end{array}$ & $\begin{array}{l}(n=23) \\
3535(546) \\
51 \cdot 0(2 \cdot 4) \\
35 \cdot 1(1 \cdot 7)\end{array}$ & $\begin{array}{l}(n=13) \\
2978(605)^{\dagger} \\
49.4(2 \cdot 7)^{\dagger} \\
33.8(1.9)\end{array}$ \\
\hline
\end{tabular}

Significance limits compared with group 1: ${ }^{\circ} \mathrm{P}<0.05,{ }^{\dagger} \mathrm{P}<0.01,{ }^{8} \mathrm{P}<0.001$ (Student's $t$ test).

compared with 11 of 25 in group 2 and seven of 15 in group 3. These abnormalities are shown in Table 2 .

\section{Subsequent two years}

Thirty nine of 40 infants in group 1 were breast fed; 11 of them for more than six months. In group 2, 18 of 25 (two for more than six months) and in group 3 six of eight (none for more than six months) infants in the custody of their biological mothers were breast fed. In group 1 two children failed appointments at the well baby clinic on one occasion each, compared with 11 on 25 occasions in group 2 and seven on 16 occasions in group 3 . One child in foster care accounts for two of these occasions but the rest were being cared for by their biological parents. The records from the well baby clinic were also studied with regard to feeding difficulties, sleep problems, infantile colic, and the frequency of infectious symptoms. There were no differences between the three groups in these respects.

During their first 18 months six children $(15 \%)$ in group 1 were treated in hospital compared with eight $(32 \%)$ in group 2 and five $(33 \%)$ in group 3. One child in group 3 died of the sudden infant death

Table 2 Abnormalities noted in the birth records

\begin{tabular}{|c|c|c|c|}
\hline & $\begin{array}{l}\text { Group } I \\
(n=40)\end{array}$ & $\begin{array}{l}\text { Group } 2 \\
(n=25)\end{array}$ & $\begin{array}{l}\text { Group } \\
(n=15)\end{array}$ \\
\hline Hyperexcitability & 2 & 3 & 4 \\
\hline Hypotonicity & 1 & 1 & 1 \\
\hline Hyperbilirubinaemia & 2 & 1 & 1 \\
\hline \multicolumn{4}{|l|}{ Slight respiratory } \\
\hline distress $^{\dagger}$ & 3 & 1 & - \\
\hline Malformations & - & $3^{8}$ & - \\
\hline Minor other & 3 & 2 & - \\
\hline
\end{tabular}

One child may have more than one abnormality.

Serum bilirubin above $300 \mu \mathrm{mol} / \mathrm{l}$.

t Extra oxygen requirement for less than 6 hours.

Two cleft palates, one ventricular septal defect. syndrome at 3 months of age. One child each in groups 1 and 2 had operations for inguinal hernia. Another two children in group 2 had operations for cleft palate, and one of these, as well as one child in group 3, underwent operation for pyloric stenosis. With two exceptions (feeding difficulties and a minor accident) the rest of the children ( 4 of 45,4 of 25 , and 3 of 15 in groups 1,2 , and 3 respectively) had been treated in hospital for acute infections.

The deviations in weights and heights of individual children at the follow up are given in Fig. 1. There was no statistically significant difference in weights beween the groups but in group 3 , three of the 14 children had weights less than -2SD for Swedish children ${ }^{8}$ compared with none in group 1 and one in group 2 . These three were all children of mothers who had continued to abuse alcohol throughout the pregnancy and they were growth retarded from birth. The child in group 2 whose weight was less than -2SD was normal at birth but deviated in infancy from its growth channel. There was a statistically significant reduction in height in group 3 compared with group 1 (Wilcoxon rank sum test, $P<0.01)$. The head circumferences of all children except one in group 3 were within the normal range. Table 3 shows the growth of the individual children in group 3 in relation to alcohol exposure in utero.

Figure 2 illustrates the abnormalities and features characteristic of fetal alcohol syndrome in individual children according to the scoring system. The mothers of the three children with the highest scores in group 3 had abused alcohol throughout pregnancy (Table 3).

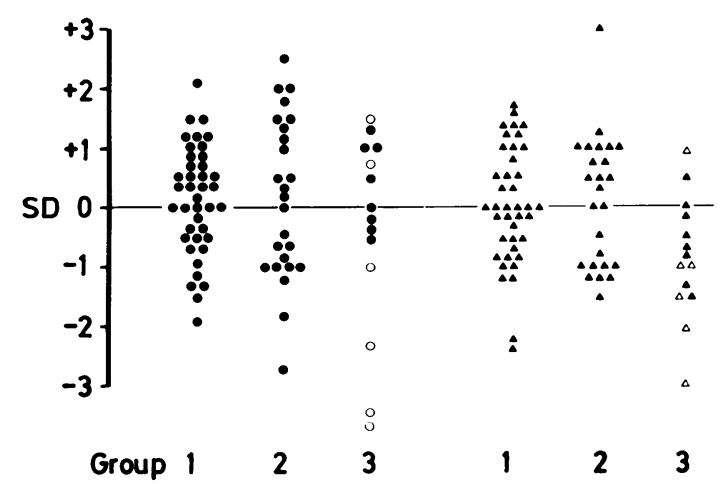

Fig. 1 Weights (O) and heights ( $\mathbf{\Delta})$ of individual children at follow up in relation to healthy Swedish children. ${ }^{8}$ The unshaded symbols represent children of mothers who continuously abused alcohol throughout pregnancy. 
Table 3 Outcome in 15 children born to alcoholic mothers

\begin{tabular}{|c|c|c|c|c|c|}
\hline \multirow{2}{*}{$\begin{array}{l}\text { Case } \\
\text { no }\end{array}$} & \multirow{2}{*}{$\begin{array}{l}\text { Continued } \\
\text { abuse during } \\
\text { pregnancy }\end{array}$} & \multirow{2}{*}{$\begin{array}{l}\text { Foster } \\
\text { care }\end{array}$} & \multirow{2}{*}{$\begin{array}{l}\text { Physical } \\
\text { abnormalities }\end{array}$} & \multicolumn{2}{|l|}{ Psychological development } \\
\hline & & & & Retarded re Griffiths scales & Behavioural disturbance \\
\hline 1 & + & - & $\begin{array}{l}\text { Growth retardation } \\
\text { dysmorphology }\end{array}$ & $\begin{array}{l}\text { Speech, eye and hand } \\
\text { coordination }\end{array}$ & Depressive \\
\hline 2 & + & + & $\begin{array}{l}\text { Growth retardation. } \\
\text { dysmorphology. } \\
\text { microcephaly }\end{array}$ & All parameters & Depressive \\
\hline 4 & - & - & - & $\begin{array}{l}\text { Speech, eye and hand } \\
\text { coordination, performance }\end{array}$ & Hyperactive \\
\hline 5 & - & + & Minor dysmorphology & All parameters & Depressive \\
\hline 6 & + & - & - & $\begin{array}{l}\text { Speech, eye and hand } \\
\text { coordination, performance. } \\
\text { personal-social }\end{array}$ & $\begin{array}{l}\text { Hyperactive, short attention } \\
\text { span, non-discriminative in } \\
\text { contact }\end{array}$ \\
\hline 7 & - & + & - & - & $\begin{array}{l}\text { Hyperactive, short attention } \\
\text { span }\end{array}$ \\
\hline 9 & + & + & - & - & $\begin{array}{l}\text { Hyperactive, short attention } \\
\text { span }\end{array}$ \\
\hline 10 & - & - & - & Performance & - \\
\hline 11 & - & - & - & $\begin{array}{l}\text { Locomotor, speech, eye } \\
\text { and hand coordination. } \\
\text { personal-social }\end{array}$ & $\begin{array}{l}\text { Hyperactive, short attention } \\
\text { span. non-discriminative in } \\
\text { contact }\end{array}$ \\
\hline 12 & - & - & - & - & - \\
\hline 13 & - & - & - & Eye and hand coordination & - \\
\hline 14 & - & - & $\begin{array}{l}\text { Failed follow-up } \\
\text { (hospitalisation of } \\
\text { mother) }\end{array}$ & Failed follow up & \\
\hline 15 & - & - & Died & Died & \\
\hline
\end{tabular}

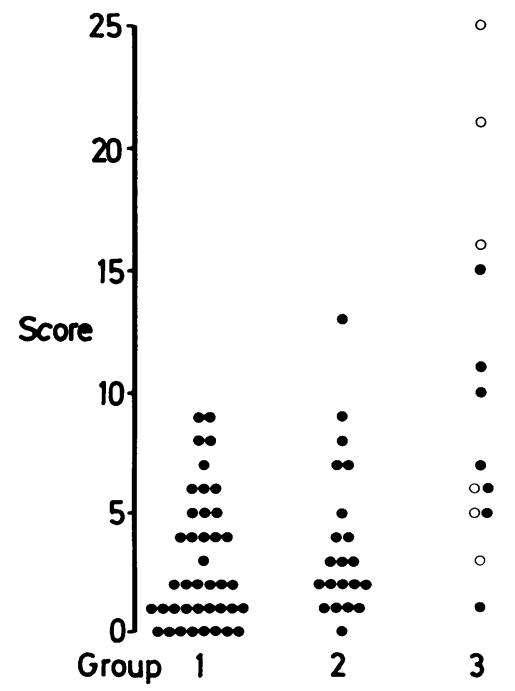

Fig. 2 Abnormalities and features characteristic of fetal alcohol syndrome in individual children at follow up.

Scoring system according to protocol. The unshaded symbols represent children of mothers who continuously abused alcohol throughout pregnancy.
Psychological development.

Development according to Griffiths scales

The results of the developmental evaluation are shown in Tables 3 and 4 . No statistically significant differences were seen between groups 1 and 2, but the speech of a large number of children in group 2 was retarded (Table 4 ). In group 3 the children were significantly retarded in three of the five parameters tested.

\section{Behaviour}

Significantly more symptoms of behavioural disturbance were seen in children in group 3 than in group 1

Table 4 Number of children with retarded ${ }^{*}$ psychological development according to Griffiths Scales

\begin{tabular}{|c|c|c|c|}
\hline & $\begin{array}{l}\text { Group I } \\
(n=40) \\
\text { No }(\%)\end{array}$ & $\begin{array}{l}\text { Group } 2 \\
(n=20) \\
\text { No }(\%)\end{array}$ & $\begin{array}{l}\text { Group } 3 \\
(n=13) \\
\text { No }(\%)\end{array}$ \\
\hline Locomotor & $3(8)$ & $2(10)$ & $3(23)$ \\
\hline Personal/social & $1(3)$ & $4(20)$ & $4(31)^{\dagger}$ \\
\hline Speech & $6(15)$ & $8(40)$ & $6(46)$ \\
\hline $\begin{array}{l}\text { Eye and hand } \\
\text { coordination }\end{array}$ & $1(3)$ & $2(10)$ & $7(54)^{\ddagger}$ \\
\hline Performance & $2(5)$ & $3(15)$ & $5(38)^{t}$ \\
\hline
\end{tabular}

- Defined as less than 4 stanine points out of 9 possible in each respective parameter. One child may show several different deviations.

${ }^{+} \mathrm{P}<0.05 .{ }^{+} \mathrm{P}<(0) \cdot 01$ compared to group 1 (Fisher's exact test). 
Table 5 Number of children with symptoms of behavioural disturbance

\begin{tabular}{|c|c|c|c|}
\hline & $\begin{array}{l}\text { Group } 1 \\
(n=40) \\
\text { No }(\%)\end{array}$ & $\begin{array}{l}\text { Group } 2 \\
(n=20) \\
\text { No }(\%)\end{array}$ & $\begin{array}{l}\text { Group } 3 \\
(n=13) \\
\text { No }(\%)\end{array}$ \\
\hline Hyperactive & $2(5)$ & $2(10)$ & $7(54)^{+}$ \\
\hline Depression & $2(5)$ & $3(15)$ & $3(23)$ \\
\hline Short attention span & - & - & $4(31)^{\dagger}$ \\
\hline $\begin{array}{l}\text { No discrimination in } \\
\text { contact with strangers }\end{array}$ & - & - & $3(23)^{*}$ \\
\hline
\end{tabular}

${ }^{\mathrm{P}<0.05},{ }^{+} \mathrm{P}<0 \cdot 01$ compared with group 1 (Fisher's exact test).

(Tables 3 and 5). Hyperactivity was the most prevalent deviant behaviour, often combined with a short attention span. These disturbances existed irrespective of whether the children were in the care of their biological or foster parents.

\section{Social situation.}

\section{Alcohol consumption}

Most of the mothers in group 2 stated in the follow up interview that their drinking habits were similar to those before the pregnancy. Among the eight mothers in group 3 who reared their children, four had relapsed into alcohol abuse and four were teetotallers. The children of the remaining six mothers in group 3 were in foster care and information on their alcohol consumption was not collected.

Measures taken by the social welfare department As shown in Table 6, significantly more families in groups 2 and 3 were on the records of the social welfare department than group 1. Most of the families in groups 1 and 2 were registered because they had received financial support- $22 \%$ and $40 \%$ respectively. These figures are significantly higher than the $4 \%$ in the general population ${ }^{9}(P<0 \cdot 001)$, and are characteristic of the residential area. No family in group 1 but four of the 25 families in group 2 and five of the eight who still had custody of their children in group 3 were on the records of the social welfare department because of parental alcohol abuse. The social authorities had mobilised both

Table 6 Support offered the families by the Social Welfare Department (SWD) during the follow up

\begin{tabular}{|c|c|c|c|}
\hline & $\begin{array}{l}\text { Group } 1 \\
(n=40) \\
\text { No }(\%)\end{array}$ & $\begin{array}{l}\text { Group } 2 \\
(n=25) \\
\text { No }(\%)\end{array}$ & $\begin{array}{l}\text { Group } 3 \\
(n=8) \\
\text { No }(\%)\end{array}$ \\
\hline Financial support & $9(22)$ & $10(40)$ & $5(63)$ \\
\hline Lay therapist & - & $2(8)$ & $4(50)$ \\
\hline Child on probation & - & - & $2(25)$ \\
\hline $\begin{array}{l}\text { Families not registered } \\
\text { by SWD }\end{array}$ & $31(78)$ & $13(52)$ & - \\
\hline
\end{tabular}

"Only families who have custody of the child are included.
Table 7 Family situation at the age of 18 months

\begin{tabular}{llll}
\hline & $\begin{array}{l}\text { Group 1 } \\
(n=40) \\
\text { No (\%) }\end{array}$ & $\begin{array}{l}\text { Group 2 } \\
(n=25) \\
\text { No (\%) }\end{array}$ & $\begin{array}{l}\text { Group 3* } \\
(n=14) \\
\text { No (\%) }\end{array}$ \\
\hline $\begin{array}{l}\text { Child living with } \\
\text { both natural parents }\end{array}$ & $39(98)$ & $14(56)^{\S}$ & $4(29)^{\S}$ \\
$\begin{array}{l}\text { Child living with single } \\
\text { mother with or without } \\
\text { stepfather }\end{array}$ & $1(2)$ & $11(44)^{\S}$ & $4(29)^{\dagger}$ \\
Child in foster care & - & - & $6(43)^{\S}$ \\
\hline
\end{tabular}

- One child died.

${ }^{+} \mathrm{P}<0.05,{ }^{8} \mathrm{P}<0 \cdot 001$ compared with group 1 (the $\chi^{2}$ test and Fisher's exact test).

voluntary and compulsory social measures to assist the families with documented parental addiction.

\section{Family situation}

All children in groups 1 and 2 had been looked after by their mothers during the entire follow up period. Six of the 14 children of alcoholic mothers were in foster care at the age of 18 months (Tables 3 and 7). Four of them were placed in foster care directly from the maternity clinic, and the remaining two after a period of less than three months in the custody of their biological mothers. As shown in Table 7 significantly more children lived with both their biological parents in group 1 than in groups 2 and 3. Ten of the 25 mothers in group 2 had separated from the child's father during the follow up period.

\section{Discussion}

The complete fetal alcohol syndrome including growth retardation, characteristic facial dysmorphology, and central nervous system dysfunction, has been reported in children of alcoholic mothers. ${ }^{5}$ Moderate alcohol consumption, equivalent to that in our group 2 mothers, has been reported to affect fetal growth. ${ }^{10}$ In our study all mothers in group 2, according to their own reports, reduced or stopped alcohol consumption after their first maternal health clinic visit. No fetal growth retardation was found in this group, supporting the assumption that preventive efforts instituted early in pregnancy are of importance. Nor did the children in group 2 show any other physical or psychological characteristics of fetal alcohol explosure. Almost half of them had retarded speech which could be attributed to postnatal environmental influences. In this group there were several factors indicating social instability, such as high frequency of separations between the parents and of registrations by the social welfare department. The many occasions of non-attendance at the well baby clinic also suggest dysfunction in 
these families. In several studies, delay in speech development has been shown to be a sensitive indicator of an unsatisfactory emotional or social situation. ${ }^{11} 12$ Fifteen per cent of the children in group 1 suffered speech delay. In a Swedish study of all 4 year old children living in a residential area similar to the one in the present study, symptoms of emotional disturbance were found in $25 \%$ of the children. ${ }^{13}$ These findings were attributed to unsatisfactory social and family conditions and the same explanation for the high frequency of speech retardation in this study is likely.

Six of the 15 alcoholic women (group 3) continued to abuse alcohol throughout pregnancy, and three of these women gave birth to children with abnormalities characteristic of fetal alcohol exposure, one of them having the complete fetal alcohol syndrome (Table 3). These three mothers registered at the maternal health clinic after the 30th week of gestation. Only one child in group 3 was normally developed in all psychological parameters and had normal behaviour. These findings suggest an adverse effect of early fetal exposure to alcohol on psychological development which cannot be completely reversed or compensated for by stopping abuse, or by an optimal postnatal environment during the first years of life. Further follow up studies are needed for a more definite evaluation of the environmental influence on the development and behaviour of these children.

Stopping alcohol abuse after the first trimester cannot reduce the documented increased risk of congenital malformations. This must not result in a defeatist attitude, however, since the increase in malformations in fetal alcohol syndrome is marginal and most are treatable. In the present study three malformations occurred in group 2 children but none resulted in permanent disability. Because of the small population the causative role of alcohol in the genesis of these malformations cannot be evaluated.

The importance of postnatal environmental influences on the psychological development of children affected by alcohol in utero is frequently cited. Parents tend to follow the child rearing pattern of their own parents. ${ }^{14}$ Most of the mothers in group 3 were reared in dysfunctional families and their childhood greatly resembled that of female abusers described in other studies. ${ }^{15} 16$ Because of the frequent occurrence of central nervous system dysfunction in children affected by alcohol during the fetal period these children may require more attention and care than other children. This must be considered when the custody of a child affected by alcohol in utero is discussed.

This study was supported by grants from The 'Expressen' Prenatal Research Foundation and the Swedish Ministry of Health and Welfare.

The authors are grateful to Gunilla Ekenstein, social worker, who undertook the interviews, and Lisbeth Hyvönen, psychologist, who performed the psychological development tests.

\section{References}

1 Jones KL, Smith DW, Ulleland CN, Streissguth AP. Pattern of malformation in offspring of alcoholic mothers. Lancet 1973;i:1267-71.

2 Olegård R, Sabel K-G, Aronsson M, et al. Effects on the child of alcohol abuse during pregnancy. Acta Paediatr Scand (Suppl) 1979;275:112-21.

${ }^{3}$ Streissguth AP, Martin DC, Martin JC, Barr HM. The Seattle longitudinal prospective study on alcohol and pregnancy. Neurobehav Toxicol Teratol 1981;3:223-33.

${ }^{4}$ Larsson G. Prevention of fetal alcohol effects-an antenatal programme for early detection of pregnancies at risk. Acta Obstet Gynecol Scand 1983;62:171-8.

5 Clarren SK, Smith DW. The fetal alcohol syndrome. N Engl J Med 1978;298:1063-7.

${ }^{6}$ Griffiths R. The abilities of babies. London: London University Press, 1954.

${ }^{7}$ Griffiths R. The abilities of young children. London: Child Development Research Centre, 1970.

${ }^{8}$ Karlberg P, Taranger J, Engström I, Lichtenstein H, Svennberg-Redegren I. The somatic development of children in a Swedish urban community. Acta Paediatr Scand 1976; Suppl 258.

9 Statistical abstract of Sweden. Sweden: 1980, 67.

${ }^{10}$ Little RE. Moderate alcohol use during pregnancy and decreased infant birthweight. Am J Public Health 1977;67: 1154-6.

11 Wulbert M, Inglis S, Kriegsman E, Mills B, Language delay and associated mother-child interaction. Developmental Psychology 1975;2:61-70.

12 Elardo R, Bradley R, Caldwell B. A longitudinal study of the relation of infants' home environments to language development at age three. Child Dev 1977;48:595-603.

${ }^{13}$ Lagerkvist B, Lauritzen S, Olin P, Tengvald K. Four-year-olds in a new suburb: the need for medical and social care. Acta Paediatr Scand 1975;64:413-20.

${ }^{14}$ Steele B, Pollock C. A psychiatric study of parents who abuse infants and small children In: Helfer $\mathrm{R}$, Kempe $\mathrm{CH}$, eds. The battered child. Chicago and London: The University Press, 1968;103-18.

15 Dahlgren L. Female alcoholics. A psychiatric and social study. (Thesis). Stockholm: Karolinska Institute, 1979.

${ }^{16}$ Larsson G, Eriksson M, Zetterström R. Amphetamine addiction and pregnancy. Psychological and medical aspects. Acta Psychiatr Scand 1979;60:334-46.

Correspondence to Dr G Larsson, Department of Psychiatry, Huddinge Hospital, S-141 86 Huddinge, Sweden.

Received 26 November 1984 